\title{
Anomalous Mechanical Behavior in Stationary Small Crack Tips about EAC for Nickel-Base Alloy
}

Fang Xiurong, Xue He, Yang Fuqiang

Xi'an University of Science and Technology, Xi'an 710054, China

\begin{abstract}
The crack tip mechanical characteristic and crack propagation rates are influenced by crack length, but the current research of environmentally assisted cracking (EAC) focuses on long crack, and small crack is usually ignored. The mechanical characteristics of small crack tips for single-edge crack panel specimens during the EAC in high temperature water were studied. The specimens were made of nickel-base alloy and the finite element method (FEM) was adopted. The results show that the stress and the strain are much higher for small crack compared to long crack, and this leads to a higher crack propagation tendency of small crack. A corrected method has been introduced to calculate the plastic zone size of small crack. The Irwin correction method can improve the accuracy of $J$ integral of long crack, but errors still exist for small crack. So the numerical method with elastic plastic fracture method has been recommended to calculated $J$ integral for small crack under larger load condition considering the lack of mature theoretical guidance about the small crack. The crack propagation process of the EAC of structure materials serviced in nuclear power plants is suggested to divide into small crack propagation and long crack propagation owing to their anomalous mechanical behaviors.
\end{abstract}

Key words: environmentally assisted cracking (EAC); small crack; stress; strain; $J$ integral

It is well known that the environment, the material, and the mechanics near to the crack tip are the most important factors affecting the growth rate of the environmentally assisted cracking (EAC) crack in high-temperature aqueous environments ${ }^{[1]}$. Since Person found small-crack effect in studying the aluminum alloy crack growth behavior ${ }^{[2]}$ in 1975, he pointed out that the service life of components, especially for high strength alloy materials, was mainly controlled by the initiation and the propagation behavior of small fatigue cracks with the scale usually identified from 0.1 to $1 \mathrm{~mm}^{[3,4]}$ in engineering. This means that the effective life of components takes most of the service life that is small crack period ${ }^{[5]}$. The mechanical behavior of short crack is obviously discriminated with long crack, which can't be explained by the traditional theories ${ }^{[6]}$. Therefore, many researches have been performed to understand the so-called anomalous behavior of the small fatigue cracks.
The pressure vessels of nuclear reactor are usually designed based on the norms of boilers and pressure vessels of ASME, which is defined by linear elastic fracture mechanics $(\mathrm{LEFM})^{[7]}$. However, the fracture failure of components has large plastic deformation when the service temperature of components is far above the brittle-ductile transition temperature in most cases. This is because the components serve in a corrosive environment, and the failure of components exhibits an EAC behavior ${ }^{[8]}$, which is the interaction among tensile stress, corrosive environment and susceptible material, such as the EAC failure of pipes made of nickel base alloy used in light water reactor environments. The continuum assumption and linearly elastic hypothesis are not valid upon calculating the stress and strain field nearby the small crack tip of EAC, so it will be a great security risk if the stress intensity factor $\left(K_{\mathrm{I}}\right)$ is associated with small crack propagation. However, it is

Received date: January 26, 2015

Foundation item: National Natural Science Foundation of China (51475362); Natural Science Foundation of Shaanxi Provincial (2015JM5257); Scientific Research Program Foundation of Shaanxi Provincial Education Department (2013JK1006)

Corresponding author: Fang Xiurong, Ph. D., Associate Professor, School of Mechanical Engineering, Xi'an University of Science and Technology, Xi'an 710054, P. R. China, Tel: 0086-29-85583159, E-mail: fangxr098@163.com

Copyright $($ C 2015, Northwest Institute for Nonferrous Metal Research. Published by Elsevier BV. All rights reserved. 
difficult to obtain sufficient experimental data because of the slow propagation rate of EAC, and a lack of mature theoretical guidance about the small crack, the stress and strain field nearby small crack tip of EAC condition is almost completely ignored in practice ${ }^{[9,10]}$.

In the present paper, the results of a detailed elastic plastic fracture mechanics (EPFM) of the stress and strain field nearby small crack under EAC condition of nickel-base alloy were reported. It is necessary to use the local stress, plastic strain and plastic zone in the stationary crack tips upon quantitative predicting the crack propagation rate and remained life of components, and the stress and plastic strain nearby small crack tip were also discussed under constant $K_{\mathrm{I}}$ and changed $K_{\mathrm{I}}$.

\section{Specimen and Calculation Model}

The single-edge crack panel model was adopted during the change of the crack length in the simulated experiments, which was expected to represent the crack tip stress and strain conditions in the entire EAC experimental process. The geometric shape and size of the panel are shown in Fig.1a.

As the crack front along the thickness of a specimen is mainly dominated by the plane strain condition in EAC experiments, the specimen could be simplified as a plane strain model ${ }^{[11]}$. The finite element mesh of the model is shown in Fig.1b, where the biquadrate plane strain quadrilateral elements were adopted in the whole model, and the mesh of the crack tip region was refined in order to obtain more detailed crack tip stress-strain data. Here $X$-axis is the opposite direction of the crack growth, and $Y$-axis is the normal direction of the crack growth in the coordinate system.

The alloy 600, widely used as structural materials in nuclear power plants, was adopted in this numerical simulation. The mechanical properties of the alloy are shown in Table 1. The stress-strain relation beyond yielding is represented as the Ramberg-Osgood equation at the loading

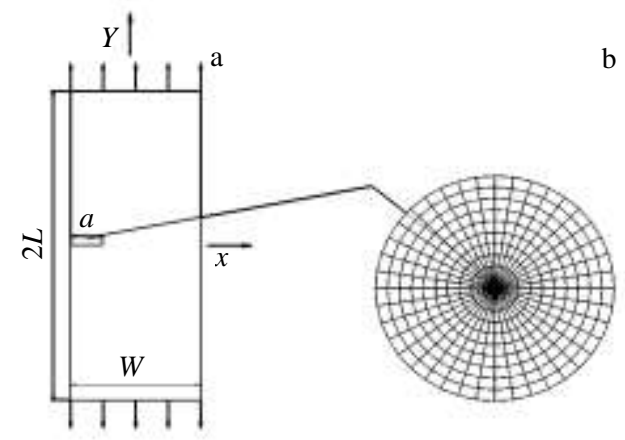

Fig.1 Single-edge crack panel model ( $L=25 \mathrm{~mm}, W=20 \mathrm{~mm})$ : (a) unilaterally cracked specimens and (b) FEM of the crack tip
Table 1 Properties of alloy 600 in PWR primary water at

\begin{tabular}{cc}
$\mathbf{3 4 0}^{\circ} \mathbf{C}^{[12]}$ & \\
\hline Properties & Value \\
\hline Yield strength, $\sigma_{0} / \mathrm{MPa}$ & 436 \\
Yield offset, $\alpha$ & 3.075 \\
Hardening exponent, $n$ & 6.495 \\
Young's modulus, $E / \mathrm{GPa}$ & 189.5 \\
Poisson's ratio, $v$ & 0.286 \\
\hline
\end{tabular}

stage, and the stress $(\sigma)$-strain $(\varepsilon)$ relation is simply regarded as a linear elastic relation at the unloading stage in this simulation. The Ramberg-Osgood equation is written as Eq. $(1)^{[12]}$

$$
\frac{\varepsilon}{\varepsilon_{0}}=\frac{\sigma}{\sigma_{0}}+\alpha\left(\frac{\sigma}{\sigma_{0}}\right)^{n}
$$

where $\sigma_{0}$ is the yield strength of the material, $\varepsilon_{0}$ is the yield strain, $\alpha$ is the yield offset and $n$ is the strain hardening exponent of the material. The stress-strain curve of alloy 600 calculated by Eq.(1) are shown in Fig. 2.

The diameter and the wall thickness of RVP (reactor vessel plant) used in pressurized water reactor (PWR) were 4400 and $225 \mathrm{~mm}$, respectively. The hoop stress and radial stress were 147 and $73.5 \mathrm{MPa}$ when the internal pressure was equal to $15 \mathrm{MPa}$ under service condition, and the range of stress intensity factor calculated were from 5 to 10 $\mathrm{MPa} \cdot \mathrm{m}^{1 / 2}$. Thus the stress intensity factor $K_{\mathrm{I}}$ with 10 $\mathrm{MPa} \cdot \mathrm{m}^{1 / 2}$ was adopted to study the stresses and plastic strains nearby a stationary crack tip ${ }^{[13]}$, and the effects of $K_{\mathrm{I}}$ on the stress and strain distribution nearby crack tip was studied with $K_{\mathrm{I}}$ changing from5 to $10 \mathrm{MPa} \cdot \mathrm{m}^{1 / 2}$.

\section{Results and Discussion}

\subsection{Stress and strain distribution nearby small crack tip}

The distribution of the tensile stress $\left(\sigma_{22}\right)$ and equivalent plastic strain $\left(\varepsilon_{\mathrm{p}}\right)$ in front of a stationary crack tip are shown in Fig.3. It can be seen from Fig.3a that $\sigma_{22}$ declines with the increase of the distance away from the crack tip at a constant crack length, but the change gradient decreases.

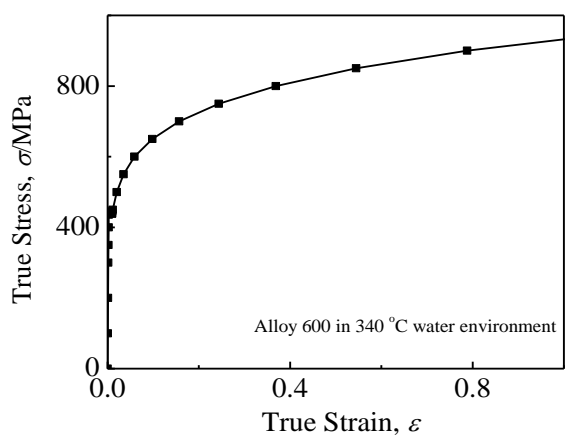

Fig.2 Stress-strain relationship of alloy 600 
Fig.3a also shows that the tensile stress decreases with the increasing of crack length, which indicates that the stress at crack tip decreases with the crack propagation. Since stress is an important parameter driving the propagation of crack, the crack propagation tendency of small crack is higher than that of long crack, and greater load condition should be adopted to keep the crack propagation driving stress as the crack propagation.

It is almost impossible to obtain the strain exactly at the crack tip as the strain singularity at the crack tip, the crack tip strain $\varepsilon$ is generally replaced by the plastic strain $\varepsilon_{\mathrm{p}}$ at a characteristic distance in front of the crack tip in the present study. The distribution of the equivalent plastic strain ahead of the stationary crack tip are shown in Fig.3b. It can be seen that the plastic strain in front of the crack tip decreases with the increase of the distance away from the crack tip. The crack tip with small crack length is surrounded by a high strain zone, and the strain might reach $2 \varepsilon_{0} \sim 5 \varepsilon_{0}$ or even higher value at the tip of EAC. But the strain at crack tip decreases rapidly with the increasing of crack length. This result indicates that the equivalent plastic strain in front of crack tip will decrease upon crack propagation, and the crack propagation tendency will reduce with the propagation of crack under constant load condition.

\subsection{Plastic zone nearby crack tip}

Since larger plastic strain needs large external force doing work, and larger plastic zone will store much more energy than smaller plastic one, the size of plastic zone is an important fracture parameter to evaluate crack propagation behavior.

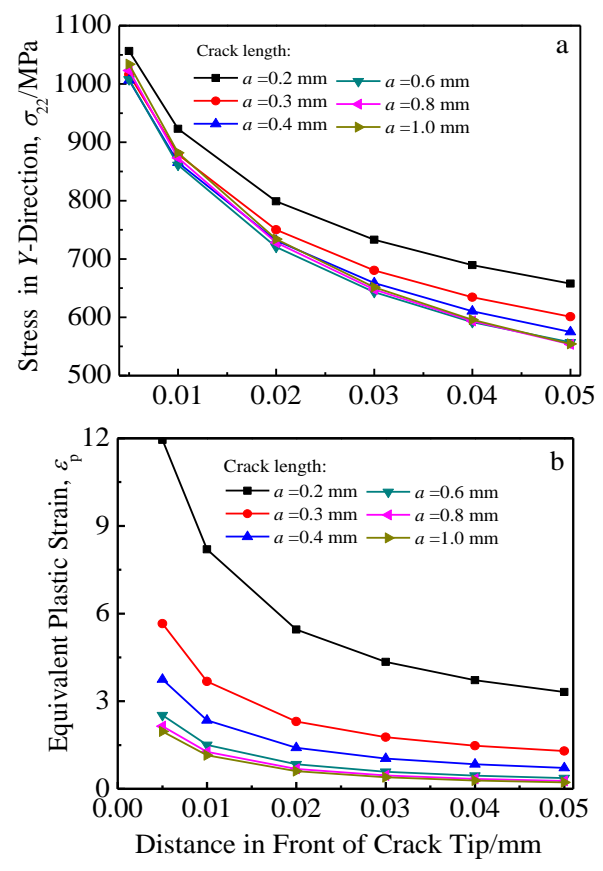

Fig.3 Stress (a) and strain (b) distribution in front of crack tip
The plastic zone nearby crack tip, which is defined using $20 \%$ equivalent plastic strain of yield strain, is shown in Fig.4. The circular area is retrieved from the crack tip with radius of $0.05 \mathrm{~mm}$, and the contours $1,2,3$, and 4 denote the plastic zone boundaries of cracks with lengths of $0.3,0.5,1$ and $5 \mathrm{~mm}$, respectively under crack tip stress intensity factor with $10 \mathrm{MPa} \cdot \mathrm{m}^{1 / 2}$. It can be seen that the sizes of plastic zones are quite different for different crack lengths. The area of plastic zone shrinks with the increasing of crack length; this indicates that the small crack stores more energy than long crack under the same load condition, a large amount of energy will be dissipated during crack propagation, and this leads to the stress and strain at crack tip release, as the stress and strain change tendency with crack length shown in Fig.3.

To evaluate the crack propagation behavior, the plastic region shape and size $r$ should be quantitatively determined. Since the small crack tip is surrounded by a high strain zone, the empirical equation is usually used to approximately define the maximum size of plastic zone by $\operatorname{LEFM}^{[14]}$ :

$$
r=\frac{1}{4 \sqrt{2} \pi}\left[1+2.5\left(\frac{\sigma}{\sigma_{0}}\right)^{2}+4\left(\frac{\sigma}{\sigma_{0}}\right)^{4}\right]\left[\frac{K}{\sigma_{0}}\right]^{2}
$$

For a plastic zone calculated by Eq.(2), $r$ is usually corrected by adding the effect of stress relaxation at crack, and this leads to the plastic zone increase to $2 r_{\max }{ }^{[15]}$. In the present study, the Ramberg-Osgood equation was used to define the mechanical properties of material, and thus the Eq.(2) can be corrected as:

$$
r=\frac{1}{2 \sqrt{2} \pi}\left(\frac{n-1}{n+1}\right)\left[1+2.5\left(\frac{\sigma}{\sigma_{0}}\right)^{2}+4\left(\frac{\sigma}{\sigma_{0}}\right)^{4}\right]\left[\frac{K}{\sigma_{0}}\right]^{2}
$$

The crack tip plastic zone sizes calculated by Eq.(3) and finite element (FE) method are shown in Fig.5, and the results show well agreements. This indicates that the plastic zone sizes of the small cracks can be well described by Eq.(3).

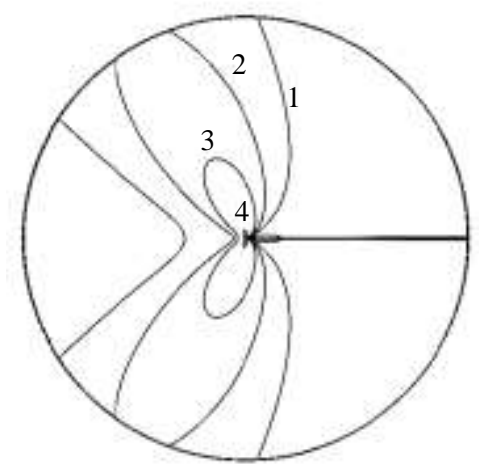

Fig.4 Plastic zones of stationary crack tips with different crack lengths: (1) $a=0.3 \mathrm{~mm}$, (2) $a=0.5 \mathrm{~mm}$, (3) $a=1 \mathrm{~mm}$, (4) $a=5 \mathrm{~mm}$ 


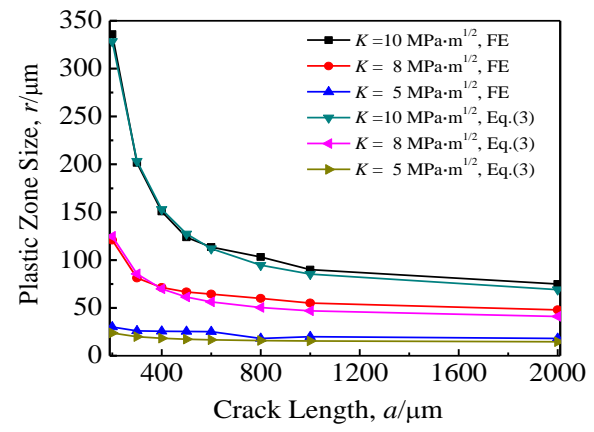

Fig.5 Plastic zone calculated by FE method and Eq.(3)

\subsection{Fracture parameter $: J$ integral}

A fracture-based approach is widely adopted in EAC research. $J$ integral, which can be explained as the deformation power, is an important parameter to quantitatively define the stress and the strain strength nearby the crack tip in EAC research. For the fracture of elastic-plastic material, the $J$ integral is corrected by adding the plastic dissipated energy ${ }^{[15]}$ :

$$
J=J_{\mathrm{e}}+J_{\mathrm{p}}
$$

where $J_{\mathrm{e}}$ is the elastic contribution, and $J_{\mathrm{p}}$ is the plastic contribution.

In linear elastic range or the crack tip with small scale yielding, the $J_{\mathrm{p}}$ is usually ignored, and the $J$ can be calculated by Eq.(5) under plane strain condition:

$$
J=J_{\mathrm{e}}=K^{2} /\left[\left(1-v^{2}\right) E\right]
$$

The $J$ integrals of cracks with different lengths were calculated by LEFM or EPFM, and the results are illustrated in Fig.6. It can be seen that the $J$ integral calculated by EPFM decreases rapidly with the increasing of crack in a small crack range, the decreasing gradient reduces with the increasing of crack, and the $J$ integral almost keep constant with long crack. The $J$ integral calculated by LEFM has little change when small crack extends to long crack. The difference of $J$ integrals calculated by LEFM or EPFM is small for long crack. While the $J$ integral calculated by EPFM is much higher than $J$ calculated by LEFM. Fig.6 indicates that the $J$ integral calculated by LEFM or EPFM has little difference for long crack. Eq.(5) can be used in the fracture of elastic plastic material with long crack, but large errors would appear when calculating $J$ integral adopting Eq.(5) under small crack condition. The contribution of plastic in Eq.(4) should not be ignored.

To eliminate the errors of $J$ integral calculated by Eq.(4), the effective crack length was introduced by Irwin:

$$
a_{\mathrm{e}}=a+r_{\mathrm{p}}
$$

Where $a_{\mathrm{e}}$ is the effective crack length by adding the crack length $r_{\mathrm{p}}$ at crack tip caused by stress relaxation, and $r_{\mathrm{p}}$ is calculated by Eq.(3) at plane strain condition.

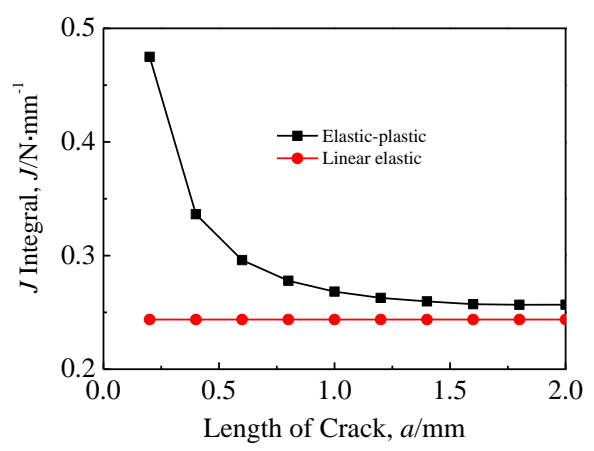

Fig.6 $J$ integrals of different crack length, calculated by EPFM and LEFM

Then the stress intensity factor $K$ can be corrected using the effective crack length:

$$
K=\alpha \sigma \sqrt{\pi\left(a+r_{\mathrm{p}}\right)}
$$

By combining Eq.(7) and Eq.(3), if the higher order therms are negligible to Eq.(3), the $K$ at plane strain condition can be calculated by:

$$
K=\alpha \sigma \sqrt{\pi a} / \sqrt{1-\frac{\alpha^{2}}{2 \sqrt{2}}\left(\frac{n-1}{n+1}\right)\left(\frac{\sigma}{\sigma_{0}}\right)^{2}}
$$

And the $J$ integral can be corrected by adopting effective crack length via substituting Eq.(8) into Eq.(5).

The $J$ integrals calculated by different methods under different load conditions are shown in Fig.7. It can be seen from Fig.7a that, for a crack with $2 \mathrm{~mm}$, the differences of $J$
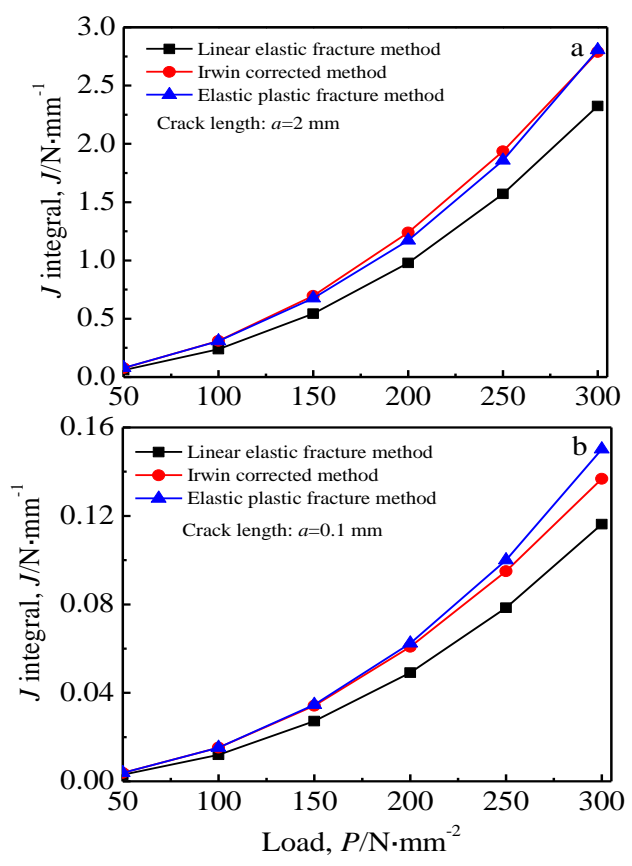

Fig.7 $J$ integral as a function of remote load 
integrals calculated by different methods are very little under small loads, but the $J$ integrals calculated by LEFM and EPFM deviates with each other with the increasing of load. By adopting the Irwin method to correct the $J$ integral calculated by LEFM, the errors seems to be eliminated when compared with the $J$ integral calculated by EPFM for a long crack. But the Irwin correction seems to have little effect for small cracks. As shown in Fig.7b, the Irwin correction indeed reduces the difference of $J$ integrals calculated by LEFM and EPFM, but the effects of Irwin correction decrease with the increasing of load, and the $J$ integral is still not accurate by Irwin correction method under small crack condition for larger loads. Thus, the Irwin correction method can be used to improve the $J$ integral accuracy for long crack, but the effect is limited for Irwin correction method to improve the $J$ integral accuracy for small crack under larger load, and the high-order terms should be taken into consideration in small crack. Since it is difficult to calculate $J_{\mathrm{p}}$ in Eq.(4), the numerical method is recommended.

\section{Conclusions}

1) The stress and the strain of small cracks are much higher than those of long cracks, and this leads to the higher crack propagation tendency of small crack compared to long crack under the same load condition. The plastic zone size of small crack is bigger than that of long crack, and the plastic zone size of small crack should be corrected considering Ramberg-Osgood equation and the stress relaxation of crack tip.

2) The $J$ integral calculated by LEFM is suitable for long crack, and the Irwin correction method can improve the accuracy of $J$ integral calculated by LEFM for long crack. While the LEFM will lead to larger errors upon calculating $J$ integral for small crack, and the Irwin correction can not eliminate the errors under larger load condition. And the high-order terms should be taken into consideration in the plastic zone size. The numerical method with EPFM is recommended to calculate $J$ integral for small crack under larger load condition.
3) The crack propagation of EAC should be subdivided into small crack propagation and long crack propagation because of the anomalous mechanical behavior of the small crack. EAC of the small crack has important influence on the degeneration process of key structures in nuclear power plants.

\section{References}

1 Xue H, SatoY, Shoji T. Transactions of the ASME-Journal of Pressure Vessel and Technology[J], 2009, 131(1): 61

2 Pearson S. Engineering Fracture Mechanics[J], 1975, 7(2): 235

3 Zheng M, Nie X, Liu X. Acta Aeronautica Astronautica Sinica $[\mathrm{J}], 1989,10(12): 636$

4 Zhang J Z, Zhang J Z, Shan Y D. Engineering Fracture Mechanics $[\mathrm{J}], 2001,68: 1591$

5 Newman J C, Phillips E P, Swain M H. International Journal of Fatigue [J], 1999, 21: 109

$6 \mathrm{Li} \mathrm{F}, \mathrm{He}$ Y T, Fan C $\mathrm{H}$ et al. Material for Mechanical Engineering [J], 2007, 32(11): 6

7 Potirniche G P, Daniewicz S R. Engineering Fracture Mechanics[J], 2003, 70: 1623

8 Xue H, Xue X F, Tang W et al. Rare Metal Materials and Engineering[J], 2011, 40(7): 1189 (in Chinese)

9 Yang F Q, Xue H, Zhao L Y et al. Rare Metal Materials and Engineering [J], 2014, 43(3): 513 (in Chinese)

10 Xue H, Sato Y, Shoji T. Journal of Pressure Vessel Technology[J], 2009, 131: 11

11 Fang X R, Xue H, Ma Y H et al. Journal of Materials Science \& Engineering $[\mathrm{J}], 2014,32(2): 238$

12 Xue H, Ogawa K, Shoji T. Nuclear Engineering and Design[J], 2009, 236(5): 628

13 Xu Y J, Yuan S. Acta Mechanica Solida Sinica[J], 2007, 20(1): 87

14 Caputo F, Lamanna G, Soprano A. Procedia Engineering[J], 2011(10): 2988

15 Kanninen M F, Popelar C H. Advanced Fracture Mechanics[M]. New York: Oxford University Press, 1985

\title{
镍基合金环境致裂稳态小裂纹裂尖力学场特殊性研究
}

\author{
方秀荣, 薛 河, 杨富强 \\ (西安科技大学，陕西 西安 710054)
}

\begin{abstract}
摘 要: 裂纹长度是影响裂纹尖端力学特性及裂纹扩展速率的重要因素, 但现有环境致裂研究中的裂纹类型主要为长裂纹而忽略了小裂 纹。本工作采用有限元数值计算的方法, 研究高温水环境下具有单边裂纹的镍基合金试样环境致裂过程中小裂纹裂尖力学特征。结果表 明小裂纹裂尖具有比长裂纹更高的应力和应变, 并使小裂纹具有更高的裂纹扩展趋势。研究中给出了计算小裂纹裂尖塑性区尺寸的修正 方法, $J$ 积分计算的Irwin修正方法适用于长裂纹，但计算小裂纹条件下的 $J$ 积分时会产生误差。提出在缺乏成熟理论指导下应采用弹塑 性有限元数值计算的方法获取准确的小裂纹裂尖 $J$ 积分。基于小裂纹与长裂纹裂尖力学特征的明显不同, 建议在分析核电结构材料环境 致裂时, 将裂纹扩展分为小裂纹扩展及长裂纹扩展阶段分别研究。
\end{abstract}

关键词: 环境致裂; 小裂纹; 应力; 应变; $J$ 积分

作者简介: 方秀荣, 女, 1972 年生, 博士, 副教授, 西安科技大学机械工程学院, 陕西 西安 710054, 电话: 029-85583159, E-mail: fangxr098@163.com 